\title{
POR UMA AMBIÊNCIA DE FORMAÇÃO CONTÍNUA DE PROFESSORES
}

\author{
CLAUDEMIR BELINTANE \\ Faculdade de Educação da Universidade de São Paulo \\ Professor de Metodologia do Ensino de Língua Portuguesa \\ bntane@usp.br
}

\begin{abstract}
RESUMO
Este trabalho propõe uma aproximação consistente entre projetos de formação contínua e uso de redes informacionais no campo da educação. Sugere o conceito de "ambiência de formação contínua" como forma de garantir um espaço de mobilização em torno da idéia de formação em serviço, para que os projetos tenham como ponto de partida as próprias demandas da comunidade. A partir dessa articulação, vislumbra novas possibilidades de conjugação de projetos de formação contínua, de pesquisa acadêmica e de autorias em rede, ressaltando a importância de uma gestão contextualizada de conhecimentos em rede, explíita e democrática o suficiente para permitir que a escola ou rede escolar seja um locus privilegiado de pesquisa, de ação pedagógica e de autorias descentralizadas.

REDEDEINFORMACÃO-PESQUISAEDUCACIONAL - FORMAÇÃOCONTÍNUAFORMAÇATODOCENTE
\end{abstract}

\section{ABSTRACT}

FORANDIN-SER MCETEACHER'SEDUCATIONENMRONMENT. Thisworkproposes a consistent approximation between continuous education projects and use of information networks in the field of education. It suggests the concept of "continuous educational environment" as a form of ensuring space for mobilization around the idea of in service learning for projects to have the community's own demands as a starting point. Based on this articulation, it envisions new possibilities for combining projects on a continuous basis, for academic research and collaborative writing of works, stressing the importance of contextualized management of network-based knowledge, explicitand democratic enough to allow the school or schoolsystem to be a privileged site for research, pedagogical action and decentralized writing of works.

INFORMATIONNETWORKS-EDUCATIONAL RESEARCH-TEACHER'SEDUCATION 
Este trabalho tem como objetivo apresentar algumas sugestões para a constituição de um modelo de formação contínua que leve em consideração a complexidade do processo quando uma rede de educadores assume o compromisso de planejar sua dinâmica de formação, levando em conta os potenciais das novas tecnologias e as demandas concretas advindas do cotidiano escolar. O eixo central de nossas sugestões encontra respaldo teórico e estratégico no campo transdisciplinar que se vem esboçando entre as concepções contemporâneas de formação contínua de professores e os potenciais de enredamento proporcionados pelas novas tecnologias comunicacionais e informacionais.

Atualmente os discursos oriundos do campo educacional e das novas tecnologias compartilham, no mínimo, de dois consensos: reconhece-se que a formação inicial de qualquer profissional é e sempre foi precária, datada e insuficiente, conseqüentemente a preocupação com processos de formação contínua, hoje, tornouse amplamente generalizada, o uso de redes informacionais vem sendo visto como desafio fundamental para a implementação e administração de processos' ${ }^{\prime}$ de formação contínua, sobretudo em países como o Brasil, onde as distâncias e as complexidades realmente se sobrelevam.

Apesar desses consensos superficiais, esses discursos ainda não exploraram devidamente os desdobramentos teóricos e práticos que a constituição do campo permite. Por enquanto os projetos de formação contínua - mesmo os tecnologicamente mais ousados - apenas assimilam, de forma muito pragmática, as tecnologias como recursos, sem dar muita atenção às suas imbricações epistemológicas. Do mesmo modo, os profissionais - por exemplo - da chamada área de e-learning vêem os formadores e educadores apenas como "produtores de conteúdo". Há inclusive um número considerável de empresas que reivindicam para si a função de "mediadores", ou seja, daqueles que constituem e produzem tecnologias e processos de mediação, ou seja, reivindicam uma interface de mediação do trabalho dos "conteudistas da educação" e as redes escolares. É como se houvesse duas ordens estanques: um bloco de conteúdo pré-produzido e a tecnologia de mediação. Esse modelo transforma a produção de conhecimento em produtos vendáveis, a empresa encomenda cursos (pacotes de conteúdos) aos pesquisado-

I Obviamente discutem-se também modelos de formação inicial neste contexto de potencialidades das redes eletrônicas e de outros recursos de educação a distância e, com certeza, tais discussões tendem a se embricar; entretanto, neste trabalho, centraremos a reflexão apenas na formação contínua. 
res e professores universitários, de preferência cursos amplos, generalistas, que podem ser reproduzidos em larga escala.

Apesar da roupagem nova trazida por esta ou aquela ferramenta ou interface gráfica, não há nada mais tradicional do que a separação entre linguagens e conteúdos. Tal dicotomização é, em parte, decorrente da aproximação tímida entre os modelos de formação contínua e as possibilidades das novas tecnologias e do conseqüente apressamento que as exigências contemporâneas suscitam, fazendo com que as novidades tecnológicas atropelem a tradição educacional.

No campo da formação contínua, os formadores universitários - demasiadamente presos ao modelo presencial, que ancora boa parte do processo educacional na verborragia do formador e no eixo teórico por ele escolhido - nem sempre estão dispostos a conhecer e a conceber novas possibilidades e modelos para o campo, sobretudo quando estão em jogo as potencialidades das novas tecnologias. É essa tradição universitária que, em geral, vem fornecendo as bases mesmo para os projetos mais democráticos e inovadores de formação contínua. Apesar de sustentar um discurso progressista, a verticalidade do processo é sempre mantida, ou seja, é sempre um grupo de professores universitários que vai dizer, nomear e tematizar as demandas e necessidades desta ou daquela rede escolar. Em última instância, são seu programa, sua bibliografia, suas concepções que, em geral, se sobrepõem aos reclamos dos professores em formação. Ainda que, em alguns casos, sondagens prévias sejam realizadas para avaliar tais demandas, o que acaba prevalecendo é a inserção de um discurso universitário (linhas e concepções pedagógicas) do qual os professores em formação captam alguns jargões e algumas técnicas isoladas.

Não raro, tais sobreposições discursivas entram em choque e acabam produzindo uma interação precária dos objetivos do projeto e das expectativas dos formandos, ou, como já apontado pelas pesquisas de Mizukami (1986) e Becker ( 1993), provocam uma certa esquizofrenia entre discurso teórico e prática pedagógica e, não raro, mesmo a interação entre pesquisa e escola fica sujeita a desacordos e desencontros, como mostra Bueno:

Os desacordos e desencontros parecem ter origem em incompreensões que procedem de ambos os lados. Por parte dos professores há queixas recorrentes de que eles e suas unidades de ensino têm sido sistematicamente considerados pelos pesquisadores como objeto de estudo, subtendendo-se aqui o duplo significado da expressão: de objeto de conhecimento e de objeto de uso. Por sua vez, nas universidades os pesquisadores mostram-se insatisfeitos, reclamando que as escolas e os professores não usam os conhecimentos gerados pelas pesquisas, e quando o fazem é para distorcê-los. De fato, por vezes as novidades pedagógicas alcançam as 
escolas, mas docentes e administradores, ao entrarem em contato com os textos produzidos no âmbito acadêmico, se dizem decepcionados com o caráter abstrato de grande parte deles e pela forma idealizada com que a realidade escolar é aí retratada. (1988, p.7-8)

Em pesquisas realizadas em várias redes escolares sobre expectativas de professores, sempre detectamos as repetitivas demandas que costumam ocorrer em todo projeto de formação contínua e que, em geral, assim se expressam: "queremos que o curso traga elementos úteis à prática escolar, "que ajude a resolver os problemas concretos da nossa prática"; "a teoria vinda da universidade está muito distante da nossa prática" etc. Não raro, o formador universitário defende-se com um jargão também bastante conhecido "nós não temos receitas pra lhe dar" e mantém seu curso, seu programa, seus objetivos e, não raro, sua soberba acadêmica acima dos clamores.

Em contrapartida, a indústria educacional tem suas receitas a oferecer: livros didáticos de má qualidade, produzidos em tiragens agigantadas para ser adotados à revelia das diferenças, singularidades e problemáticas regionais; softwares que reproduzem as mais velhas e obsoletas concepções educacionais; cursos a distância baseados no primado da redução dos custos por supressão da figura do educador e na exploração dos recursos baratos da reprodutibilidade e da disponibilidade automáticas; programas de formação a distância no formato de produtos preparados para amplos mercados; enfim, receitas ruins que acabam sendo maquiadas pelos jargões oriundos do discurso universitário. Todos os produtos oferecidos são construtivistas, promovem a autonomia, estimulam a interdisciplinaridade, permitem práticas includentes, favorecem habilidades $x$ e $y$, formam o cidadão consciente, desenvolvem o senso crítico etc.

Quando uma obra ou projeto de formação contínua tem como objetivo aproximar-se realmente do cotidiano escolar, ou seja, fazer com que a transposição didática das teorias vá ao encontro das demandas autênticas, essa discussão do fornecer a receita ou um método ao professor sempre reaparece. É o caso, por exemplo, da coleção Aprender e Ensinar com Textos, cuja produção resultou de aproximações entre universidade e escola públicas:

A princípio hesitamos em atender a essa demanda, pois sempre nos recusamos a fornecer receitas de trabalho aos professores, fórmulas mágicas que eles pudessem aplicar com a ilusão de resolver as dificuldades próprias do trabalho com a linguagem e com os novos textos em sala de aula. Mas esses professores nos convenceram de que fornecer um instrumental mínimo, como sugestão de trabalho possível, não 
significa necessariamente fornecer receitas. E que valia a pena tentar superar uma dicotomia antiga, propondo algo que não fosse nem a pura técnica nem a aplicação pura e simples de técnicas de leitura ou de métodos de ensino. Em vez disso, apresentar alguns exemplos escolhidos de modo a dar conta de uma variedade mínima de textos e divulgar a utilização de instrumental analítico e de princípios teóricos [...] (Chiappini, 2000, p.II).

Deparamo-nos de chofre com essa situação em uma pesquisa recente com educadores da rede da Fundação Bradesco, cujo objetivo era coletar informações para a implantação de um curso de formação contínua na área de ensino e leitura. Vejamos um trecho extraído de nosso relatório da pesquisa:

A grande maioria vê problemas tanto nos cursos de formação de professores como nas abordagens teóricas, afirmando que as teorias não dão conta da realidade, que a prática é mais complexa que a teoria. Argumentam ainda que boa parte das teorias trabalha com alunos ideais e atribui pouca atenção às diferenças, aos cruciais problemas de sala de aula.

Alguns questionários, embora poucos, chegam a realçar que a grande aprendizagem do professor se dá na prática, sugerindo, inclusive, que algumas teorias educacionais poderiam até ser dispensadas.

Vejamos algumas expressões colhidas nos questionários:

- Prática está distante da teoria.

- As teorias da oralidade não auxiliam nas práticas da escrita; faltam estratégias de motivação.

- As estratégias não atingem os alunos com problemas de aprendizagem mais sérios.(Belintane, 2000, p.5)

Se atualmente o discurso educacional mantém prevenções diante do positivismo ou mesmo afirma estar consciente do idealismo presente em suas intervenções e do alcance limitado de suas teorias e concepções, o mesmo não se verifica no cotidiano escolar. Há, no imaginário escolar docente, sempre uma esperança de que uma nova teoria, um novo material didático - realmente eficiente venha erradicar os problemas básicos da escola. Essa esperança e essas soluções imaginariamente sempre adiadas casam bem com as sucessivas ondas de novas propostas, de novas linhas e parâmetros, já que nem sempre tais sucedâneos possuem humildade suficiente para prevenir a escola de que sua formulação não é uma panacéia. Mesmo quando previnem, não deixam de sustentar um discurso positivista, deixando entrever que há na educação um conjunto de saberes que pode resolver os graves problemas educacionais do país. 
Acompanhando essas sucessões, tendo assimilado os jargões técnicos do discurso educacional, os produtos das novas tecnologias e do ensino a distância inserem-se no mesmo rosário de promessas. Só que em vez da relação presencial, do contato direto entre formandos e formadores, temos as vídeo e teleconferências, os pacotes de cursos via Internet ou mesmo os já tradicionais programas educativos de TV e rádio.

Olhando de um ponto de vista mais amplo, mais recuado, o que vemos é que o cotidiano escolar e o saber oriundo dos centros universitários, da pesquisa científica, continuam polarizados, engendrados a partir da relação produção-consumo. É exatamente nesse grande intervalo entre produção e consumo que as "empresas mediadoras" passam suas bateias, já que sempre será possível contar com a predisposta denúncia de que as fórmulas educacionais não funcionam como deveriam. Daí é um pulo para aceitar o argumento de que a educação contemporânea só vai assegurar sua eficiência por meio de algum milagre eletrônico.

A grande força desses argumentos é que eles possuem uma aparente camada de auto-evidência que induz o educador incauto a concluir, sem nenhum esforço, que é muito mais fácil aprender diante de um vídeo do que diante de um livro, que os livros podem ser transpostos para CDs e redes, que a grande quantidade de informação disponível pode-se transformar imediatamente em saber, em qualidade de ensino, em potencialização de aprendizagens. Por outro lado, há também a resistência reacionária daqueles a quem Esteven Johnson chamou "Os neoluditas que querem que imaginemos o computador como uma traição à inteligência mais lenta, mais concentrada do livro..." (Johnson, 200 I, p. I2).

Diante desse quadro desolador, como conciliar projetos de formação contínua com a complexidade das demandas escolares e, ao mesmo tempo, aproveitar as experiências interessantes advindas das novas tecnologias, sem cair na oferta de modelos ou de métodos miraculosos? Como construir possibilidades para um discurso mais vacilante, menos positivo, mais militante, que permita à relação universidade-escola safar-se dessa polaridade produção-consumo e constituir uma interlocução mais duradoura, mais imbricada e implicada?

Há algo de revolucionário na expressão "formação contínua". Quando tomada de uma forma utópica e livre, ela nos oferece imagens interessantes que permitem entrever uma interação mais profícua entre pesquisa universitária educacional e rede escolar pública. A idéia de continuidade leva-nos inevitavelmente à idéia de memória coletiva. Se há uma continuidade, ela não deve dizer respeito tão simplesmente à continuidade de estudos de um professor, de uma área, de uma disciplina. O que continua de verdade e possui uma memória pública e coletiva é a escola, a 
rede escolar e suas histórias, e - se quisermos sonhar - sua relação de complementaridade com a rede universitária - locus de origem da formação inicial.

Do mesmo modo, o que pode haver de mais útil e potencializador nas novas tecnologias, nas redes computacionais e comunicacionais são suas possibilidades de dinamizar interações, preservar e disponibilizar memórias e não, de forma alguma, esse culto mercadológico a suas potencialidades de reproduzir e redistribuir produtos milagrosos. Para distinguir bem a conjunção desses campos, é preciso lembrar que uma coisa é um produto, um pacote a ser reproduzido (seja curso presencial, seja software), outra coisa é um projeto construído a partir das necessidades contextualizadas, a partir das demandas autênticas e do enredamento - desde o início - de todos os participantes.

Assim, podemos imaginar que há algumas afinidades originárias entre a idéia de formação contínua de educadores e as potencialidades das redes informacionais, sobretudo se levarmos a sério que a formação contínua diz respeito ao grupo de professores, a um coletivo, à escola e à sua comunidade regional, à rede escolar geral e suas políticas públicas, à universidade e seus programas e projetos. Para que esse amplo enredamento não redunde no conceito burocrático e hierárquico de mera rede administrativa de controle e na submissão aos interesses da sanha mercadológica, é preciso contar com os potenciais das dinâmicas redes informacionais e com generosos projetos de parceria e, de preferência, parcerias e convênios a longo prazo que estreitem cada vez mais os laços entre ensino e pesquisa.

$\mathrm{Na}$ seção seguinte, apresentaremos as linhas gerais de um projeto que estamos propondo como um exemplo - ainda vacilante, descontextualizado e utópico, mas que tenta apontar um caminho entre produção de conhecimento educacional e formação contínua de educadores nesse contexto de novas tecnologias e complexidades de toda ordem. Desde já é bom lembrar que a idéia de modelo aqui é epistemológica, ou seja, não tem as pretensões pragmáticas e mercadológicas,

embora aceite o desafio de tentar sistematizar ações e interações no campo da formação contínua e da informática educacional.

\section{ESBOÇO DE UM MODELO: UMA AMBIÊNCIA DE FORMAÇÃO}

As possibilidades de enredamento, de fluxo ágil de informação, de manejo seletivo de memórias, de descentralização da informação e de domínio dos processos de interação que as redes computacionais permitem, levaram-nos a pensar um novo conceito que possa também engendrar a possibilidade de um modelo de formação contínua em rede. 
Levando em consideração que os cursos e programas de formação contínua nem sempre estão preocupados com esse aspecto mais revolucionário da expressão "contínua", com a idéia de continuidade, que pressupõe a preservação e dinamização de memórias coletivas, nosso modelo procura sistematizar uma "ambiência coletiva" suficientemente estruturada para dinamizar interações e preservar projetos, planos, histórias, acervos etc. de tal modo que a escola ou rede escolar possa apostar em sua autonomia e na gestão de suas próprias demandas. Vejamos, na seqüência, uma definição ainda vacilante, mas que já aponta para um arranjo inicial da dinâmica escolar em rede.

Uma "ambiência de formação" é o complexo enredamento subjetivo que se dinamiza a partir das diversas possibilidades de interação, produção intelectual, manejo e constituição de acervos, quando um coletivo educacional assume, explicita e coloca em jogo, entre outros, alguns compromissos fundamentais:

I. Concepção educacional que aceite estabelecer relações metodológicas e pragmáticas com as potencialidades midiáticas contemporâneas, levando em conta parâmetros mais generosos (menos comerciais) de autoria, de interação, de manutenção e uso coletivo de acervos, de obras e de recursos e materiais didáticos em geral.

2. Prática interativa, de enredamento, que permita a cada um dos participantes interagir livremente com todos os outros e vice-versa, sem hierarquização, levando-se em conta que cada participação, além de trazer, para a ambiência, problemáticas e contribuições que sua atuação local suscite, deva estar preparada para estimular pesquisas, promover e institucionalizar novas formas de autorias, constituindo e disponibilizando acervos em redes específicas.

3. Rede constituída de forma coesa, a partir de mobilizações regionais ou de objetivos e propósitos mais ou menos semelhantes, ainda que suas concepções e linhas teóricas possam ser divergentes².

4. Predisposição para assumir e administrar seu próprio projeto de formação contínua.

2 Dois exemplos aparentemente divergentes: a rede municipal de São Paulo, pela configuração mais autônoma de sua rede burocrática, em cuja malha cada Núcleo de Ação Educativa NAE - pode formar uma rede aberta, mas coesa, predisposta à interação com os outros NAEs e outras redes; a rede nacional da Fundação Bradesco, constituída por 37 escolas 
5. Predisposição para investir em formação de professores e em novas tecnologias e, sobretudo, para estabelecer convênios com universidades.

A apresentação geral de uma definição dessa "ambiência" causa-nos - e provavelmente também no leitor - uma certa sensação de utopia agigantada ou de discurso entusiasmado com propensão a não sair do papel. De fato, diante do estado caótico a que chegou a escola pública brasileira, e da sensação de impotência e de falseamento que estão sempre presentes quando contrapomos saber educacional universitário e realidade escolar, é natural que qualquer proposta mais ousada seja recebida com ceticismo, sobretudo quando estamos acostumados a reduzir nossas reivindicações para a escola pobre a políticas compensatórias (merenda, bolsa-escola, livros não consumíveis etc.).

De nossa parte sabemos que estamos lidando com o delicado fio das utopias e com o emaranhado das complexidades contemporâneas, no entanto, temos plena consciência de que propostas novas são necessárias para fazer frente às novas demandas, sobretudo essas que põem o aluno da escola pública diante de um mundo tecnologizado que vem dando azo ao mais novo paradoxo: um mundo que acena com gigantes potenciais de interação e, ao mesmo tempo, engendra com muita facilidade perversos mecanismos de exclusão social. Diante dessas novas demandas, temos certeza de que nossa definição de "ambiência de formação docente" pode significar um passo interessante para o próprio conceito de formação contínua e para implementar trabalhos coletivos e ambientes mobilizantes.

A palavra "ambiência" não é novidade nas discussões sobre informática e educação, todavia, seu uso é mais comum na arquitetura. Para os arquitetos, uma ambiência é um meio físico, mas, ao mesmo tempo, estético e psicológico planejado para as interações humanas. Já a expressão "ambiência de formação docente", que estamos tentando cunhar, extrapola um pouco essa definição da arquitetura, porque põe como centro a mobilização e os processos de intersubjetivação que esta implica. Ao assumir a palavra "ambiência", estamos colocando no devido lugar a palavra "ambiente", de largo uso na informática, que, em geral, implica a idéia de virtualidade. Nossa "ambiência de formação docente" procura integrar o conjunto das interações presenciais ao das possibilidades virtuais, ou seja, qualquer processo

espalhadas por todo o território brasileiro, que apesar da rarefação e extensão geográficas, conta com uma invejável coesão midiática, suficiente para que as demandas e propostas de cada escola possam ganhar relevo no contexto da rede geral. 
de formação de professores deve levar em conta tanto as necessidades de encontros presenciais como também as possibilidades de manejo de informações em ambientes informacionais. Enfim, fica pressuposto um foco de resistência: as interações presenciais, a mobilização são imprescindíveis em qualquer projeto educacional.

Do mesmo modo não podemos confundir uma "ambiência de formação docente" com uma interface gráfica. Há no mercado uma infinidade de aplicativos para e-learning, que simulam ambientes de formação com suas possibilidades de interação síncronas e assíncronas, mas que, na verdade, não passam de suportes para cursos on-line; tais ambientes gráficos são - como os livros didáticos - genéricos, feitos para multidões. Do mesmo modo, não se trata de um site ou "portal" que disponibilize informações para todos, mesmo levando em conta que tais ambientes disponibilizem materiais e informações da área educacional (como os portais do Ministério da Educação e das secretarias de educação). Esse uso dos recursos reproduz a mesma verticalidade da transmissão do saber acadêmico, ou seja, não engendra um compromisso mais denso com o cotidiano escolar. Alguns cursos de formação contínua mantidos pelo Ministério da Educação e Cultura MEC -, como o "Um salto para o futuro", que é baseado em material impresso e programas televisivos, chegam a contar com telepostos e telessalas e com uma recepção monitorada; no entanto, também se inserem no paradigma da verticalidade, ou seja, um centro que repassa "conteúdos". Barretto, Pinto e Martins, analisando os resultados da aplicação desse programa (duas avaliações, 1992 e 1997) mencionam que a forma pela qual esse arregimenta os cursistas não influencia a escola:

Outro aspecto que merece ser discutido aqui é que o Programa, ao trabalhar com cursistas que se inscrevem voluntariamente para freqüentá-lo, possui uma audiência, em princípio, originária de diferentes estabelecimentos de ensino. Desse modo, ele não influencia diretamente a dinâmica da escola, uma vez que o professor isolado, ainda que sensibilizado pelas mudanças propostas no curso, não encontra, via de regra, um ambiente propício à discussão e à adoção de inovações ao retornar ao seu ambiente de trabalho. (1999, p.98)

Já uma "ambiência de formação docente" é antes de tudo um compromisso complexo, uma mobilização coletiva em torno da construção dos projetos da escola ou da rede educacional e que conta com recursos informacionais e comunicacionais para garantir, entre outras possibilidades, alguns compromissos essenciais da formação em serviço. 


\section{USO PRIORITÁRIO DOS POTENCIAIS INFORMÁTICOS COMO DINAMIZADORES DE PROCESSOS}

A relação entre regional e universal deve-se dar na "ambiência" a partir de uma dinâmica de continuidade e ruptura dialética, ou seja, levando em consideração a história e as singularidades do grupo e de sua regionalidade. Os potenciais mais revolucionários das novas tecnologias permitem sistematizar processos de tal modo a dar relevo ao regional e a permitir uma integração mais crítica entre produção e consumo.

No entanto, do mesmo modo que o livro - em sua história - criou uma separação rígida entre autor e leitor, as empresas das tecnologias educacionais, ao contar com uma reprodutibilidade de baixo custo, tendem a fazer o mesmo, ou seja, reduzir as possibilidades revolucionárias de interação e de monitoramento de processos e apostar em vendas de produtos novidadeiros. Tomando como exemplo o campo da alfabetização (que em breve poderá contar com o revolucionário recurso "escrever-com-a-voz" - um golpe quase mortal na tradição representalista da cultura ocidental), em vez de um processo de pesquisa buscando intercâmbio com a realidade local e seus graves problemas, poderemos ter novas panacéias em belas embalagens "construtivistas", "sociointeracionistas" etc.

Atualmente, há no mercado várias empresas oferecendo, por meio de franquias, materiais didáticos com propostas de formação contínua embutidas no produto. Pacotes fechados de apostilas - versões encadernadas ou em suportes eletrônicos - com serviço de "formação contínua a distância", constituindo um produto acabado, "bom" para toda escola e para qualquer realidade. Um pacote desse tipo põe no lixo a autoria do grupo, as possibilidades de emergência das singularidades e desafios regionais, além de subordinar toda e qualquer iniciativa criadora a essa autoria distanciada e despersonalizada.

É importante pôr em relevo que as novas tecnologias têm potenciais para dinamizar as autorias regionais, pois trazem o paradigma do "faça-você-mesmo", da bricolagem, da autoria coletiva. Podemos intervir em toda e qualquer autoria nesse paradigma, uma boa autoria, além de abrir, antever e abrir as necessárias lacunas em seu discursos para as interações, incentiva-as e sabe, de antemão, que sua essência revolucionária é o processo e não o produto. Dito de outro modo, uma autoria de qualidade é aquela que gera uma significância tal que põe o interlocutor em estado de co-autoria, predisposto a cotejar as armações teórico-práticas de seu co-autor à sua regionalidade, ao seu contexto de sala de aula. 
O que é insuportável para as empresas que vivem do fácil lucro da reprodutibilidade em larga escala é que o produto universalista do tipo "pau pra toda obra" já não condiz com os paradigmas atuais, embora ainda se encontrem imensas fatias de mercado constituídas sobretudo pelas escolas privadas de baixa qualidade. As reivindicações regionais, os desafios propostos pelas singularidades requerem processos, ações mobilizatórias, linguagens contextualizadas e uma prontidão para rejeitar os subprodutos e os apressamentos eufóricos das novas tecnologias.

É preciso insistir: se há algo de revolucionário nas novas tecnologias de mediação, são exatamente essas possibilidades de permitirem um compromisso dialético entre os campos de informação e conhecimento mais universais e os mais contextualizados, os mais suscetíveis às diferenças regionais. Diferentemente das autorias do paradigma gráfico, nesse novo campo, as autorias podem ser abertas e recontextualizáveis. Nesse sentido, qualquer pretensão à elaboração de pacotes genéricos deve ser refutada pela vigiância da rede ou posta no seu devido lugar de produto perecível e de alcance muito limitado.

\section{CONSTITUIÇÃO E PRESERVAÇÃO DE UMA MEMÓRIA COLETIVA DOS PROCESSOS DO GRUPO}

É a partir da projeção, explicitação e gestão de uma memória coletiva que a ambiência dá concretude à sua existência, explorando com radicalidade o conceito de "continuidade", sobretudo em relação aos seus próprios processos de formação. É ela que vai permitir ao grupo de educadores exercer uma crítica concreta sobre as propostas oriundas das universidades ou centros formadores, evitando assim as sazonalidades, as propostas descomprometidas, as descontinuidades e as sobreposições discursivas. Ao avaliar os processos passados, os programas, as bibliografias, os métodos e técnicas já utilizados, o grupo de educadores saberá inserir suas novas demandas e, ao mesmo tempo, escolher e criticar as interferências exteriores. Do mesmo modo, a pesquisa universitária também deverá perceber que as continuidades e rupturas possíveis no processo não devem ser sempre favoráveis ao pesquisador ou formador - ou seja, o que se quer aqui é tornar mais concreto o jargão pedagógico de que é sempre preciso considerar que o formando é um sujeito, que tem cultura, saber e história. Talvez, a partir desse confronto, as propostas educacionais e as expectativas dos professores possam ser deslocadas daquele imaginário que sempre pressupõe que o formador traz a receita milagrosa. Do cotejo entre história, demandas autênticas e pesquisa deve nascer a consciência de que entre o saber e a realidade há e sempre haverá surpresas e ruídos e que o 
verdadeiro processo a que se aspira, na busca do conhecimento, nasce do reconhecimento das diferenças, das impossibilidades de acoplamentos perfeitos. Com uma boa memória, os formadores podem ser deslocados dessa posição fálica, dessa vocação para preencher o desejo alheio; e, aproveitando-se do mesmo deslocamento, os formandos poderão, talvez, lidar com um jogo mais real entre suas expectativas e as possibilidades limitadas das teorias.

\section{PRÁTICA PEDAGÓGICA E PRODUÇÃO DE CONHECIMENTO EDUCACIONAL: NOVAS POSSIBILIDADES DE AUTORIAS}

A formação contínua, se for realmente contínua, exige um cotidiano de estudos e pesquisas. Para se dar conta de um bom programa de ensino é preciso um domínio razoável das teorias e conhecimentos e técnicas que sua execução pressupõe.

Os recursos de hipertexto e de interatividade permitem a construção coletiva de programas e currículos e a vinculação de seus tópicos a unidades de estudos teóricos, a oficinas de construção de material didático, a painéis de críticas e sugestões. Para uma "ambiência de formação docente" é fundamental que a necessidade de busca de formação parta dessa lida concreta com o currículo, e que, nesse vaie-vem entre prática docente e busca de mais formação, a autoria do grupo seja posta em relevo. Antes de buscar formação exterior, é imprescindível explorar os potenciais internos, sobretudo aproveitar as boas experiências, registrá-las e disponibilizá-las.

Tomemos mais uma vez o exemplo da alfabetização, vejamos algumas possibilidades de links entre itens curriculares (cf. esquema adiante) e possibilidades de acervos, armações hipertextuais que permitem um processo de formação contínua rigorosamente contextualizado, com "receitas", teorias, acervos regionais, experiências de outrem etc. e um sem-número de outras boas invenções.

É importante notar que o controle processual permitido pelas novas tecnologias já aponta para uma administração complexa de processos, técnicas e informações. A visibilidade de programas e currículos transforma o processo educacional em oficina de produção, dinamizando o trabalho coletivo e tornando mais pública a função docente e suas demandas.

A partir dessas projeções podemos antever um futuro para a produção de um bom material didático: deve ser antes de tudo uma matriz gerativa, predisposta à interação, à recepção, à aceitação de co-autorias e à promoção de intercâmbios entre o saber mais universal e o regional. Um exemplo: um material didático pode 


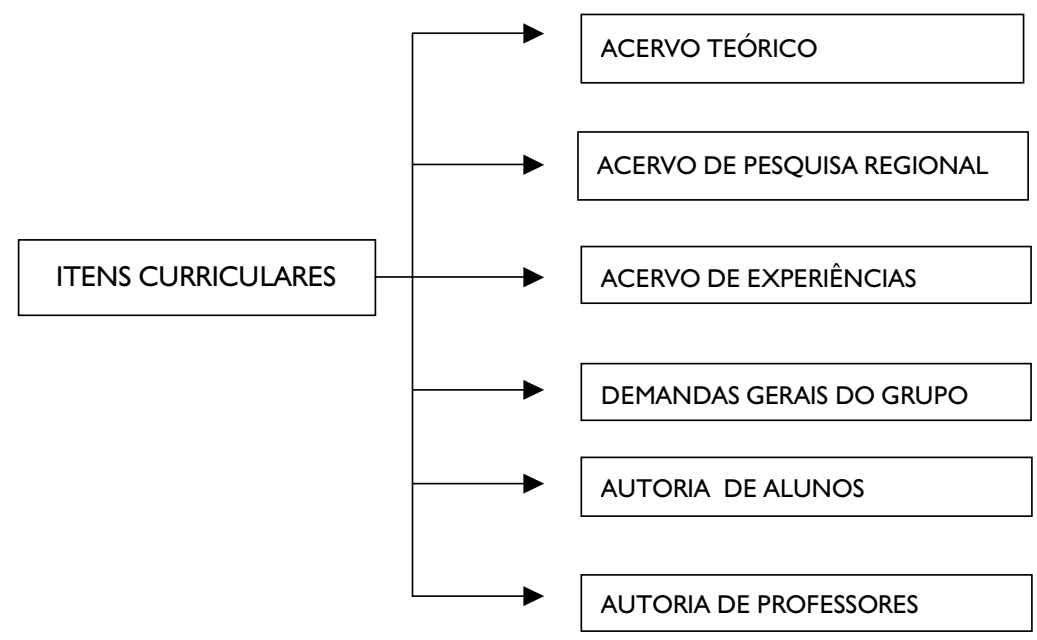

começar com uma estrutura genérica em suporte eletrônico, com base na qual novos módulos possam ser gerados de acordo com os interesses e as peculiaridades regionais, combinando, de acordo com as finalidades, suportes gráficos e eletrônicos. Uma rede educacional pode encontrar soluções interessantes nessas combinatórias de suportes e de meios.

Diante dessas exigências, o livro didático, feito para o amplo mercado nacional, já está no limite de seu paradigma. Do mesmo modo, o Programa Nacional do Livro Didático, do Ministério da Educação, já tem por que repensar e redirecionar essa imensa máquina de subsídio editorial. A busca de materiais alternativos, com possibilidades de intervenções das autorias regionais e de combinação entre suportes e meios (meios eletrônicos e formação de bibliotecas, por exemplo) deverá dar a tônica das próximas décadas, necessidade já parcialmente anunciada pelo Ministério das Ciências e Tecnologia, no capítulo 4 (Educação na Sociedade da Informação), do Livro verde:

É preciso criar mecanismos para a produção de conteúdos por parte da comunidade. A produção e o uso de conteúdos que reflitam os interesses e explorem a diversidade da riqueza cultural em todos os espaços, de áreas periféricas e rurais, de minorias e de grupos com interesses afins devem ser apoiados, inclusive com uma contribuição adicional para reduzir as disparidades regionais e sociais, abrindo oportunidades para todos os tipos de registro e difusão de manifestações e idéias. (Takahashi, 2000, p.65) 
O capítulo 5 deste oportuno manifesto enfatiza a relação entre conteúdos ${ }^{3}$ e identidades culturais e chama a atenção para a importância do planejamento de ações que "sirvam aos interesses das identidades culturais do País" (p.60), como forma de fazer frente aos planos e projetos globalizantes. É preciso que as culturas regionais garantam possibilidades de expressão e de cotejo com os conhecimentos advindos do mundo globalizado, e entrar no novo paradigma da autoria descentralizada na produção de material didático é avançar no sentido dessas ações referidas no manifesto.

\section{PESQUISA UNIVERSITÁRIA E REDES ESCOLARES: DESMONTANDO A RELAÇÃO SUJEITO-OBJETO}

A pesquisa universitária - sobretudo a praticada nas universidades públicas de boa qualidade - deve buscar uma relação mais efetiva com as redes escolares, tentar lidar com a dinâmica viva do cotidiano escolar e posicionar-se mais concretamente em relação aos desafios nacionais e regionais. Qualquer teoria ou linha pedagógica advinda do exterior deve passar pelo crivo das demandas autênticas e da história de formação dos professores e de suas singularidades regionais; antes de instituir um imaginário positivo e um discurso competente, deve procurar enxergar suas diferenças, lacunas e desajustes em relação à especificidade regional.

Em contrapartida, as redes escolares devem aproximar seus projetos da pesquisa universitária e, se possível, manter um intenso intercâmbio presencial e virtual com as comunidades universitárias. A relação entre produção de conhecimento e aplicação é que vai motivar a necessidade de novos planos de formação contínua. Nesse sentido, não é vantagem para a rede escolar adquirir pacotes de formação contínua ou de cursos sazonais sem estreitar essa proximidade, sem cotejar suas demandas com o estado da arte da pesquisa educacional.

O enredamento informacional passa a ser indispensável para dar conta da complexidade dessas relações. A velha dicotomia sujeito-objeto da pesquisa tradicional começa a perder a polaridade e ganhar a dimensão da co-autoria e dos desafios coletivos. Nesse sentido, um bom projeto de formação contínua não deixa de ser um campo de pesquisa, lugar de dúvidas e de incertezas compartilhadas, fluxo autêntico da intersubjetividade e não apenas de uma emissão-recepção fixa e imaginária nos moldes de uma competência a toda prova.

3 Infelizmente, ainda utilizam a palavra conteúdo, melhor seria a expressão "produção de conhecimentos", não?! 
A formulação de uma ambiência de formação contínua traz também um profícuo campo de pesquisa interdisciplinar entre a educação e a informática, cuja preocupação fundamental seria o trabalho contextualizado de pesquisar ferramentas e arquiteturas de interfaces gráficas que, diferentemente das existentes no mercado, procurem favorecer as ambiências coletivas de trabalho, de formação e de autorias coletivas. As empresas de e-learning não estudam a especificidade das redes públicas, antes importam o vocabulário, as ferramentas dos "treinamentos empresariais"; nesse sentido, produzem cursos sazonais, sem os compromissos com a idéia de continuidade, que é a que realmente favorece autonomização da rede escolar e de cada unidade da rede.

Para encerrar, convém retomar e reforçar aqui alguns contra-argumentos já mencionados neste trabalho. Uma proposta como esta não deixa de parecer excessivamente utópica, sobretudo se levarmos em conta o estado da escola brasileira, o baixo nível de alfabetização tecnológica, os altos custos dos equipamentos, as dificuldades de conexão, as dificuldades políticas impostas pelo predomínio das imensas redes burocráticas - como a rede estadual de São Paulo, e tantos outros problemas, alguns, talvez, até mais complexos do que esses apontados. Da forma como a educação vem caminhando, tudo parece favorecer aos vendedores de pacotes, à reprodutibilidade fácil e econômica, às decisões verticalizadas que impõem pacotes de formação contínua sem que as escolas possam sequer elencar suas prioridades, à indústria do material didático, enfim, às políticas mais populistas.

Entretanto, vale a pena insistir nessa utopia porque idéias como as veiculadas neste artigo abrem perspectivas para uma escola autônoma e mobilizada, aposta em um novo modelo de pesquisa educacional, assume novas possibilidades de tratar o conhecimento e projeta uma intensa dinâmica entre pesquisa educacional acadêmica e redes escolares. E também porque as novas tecnologias, sobretudo as redes informacionais, a cada dia, popularizam uma novidade "impossível" e engendram transformações de hábitos e atitudes que até mesmo os mais céticos são obrigados a reconhecer e a aderir.

A escola pobre pegou apenas a rabeira do apogeu do paradigma construído a partir do cânone ocidental da representação. Agora, diante das novas e radicais possibilidades de fala-escrita-leitura, que se esboçam com vigor nos cenários comunicacionais e que já surgiram questionando a representação, a escola popular parece pronta para consumir as sobras do velho paradigma e, se não se organizar, talvez possamos ter uma divisão ainda mais radical que a proporcionada pelo mundo editorial burguês, uma divisão que deixará a escola pobre eternamente na mara- 
nha ${ }^{4}$ (ou má aranha?) da rede burocrática, a aceitar as demandas deste ou daquele grupo político em ascensão e a se iludir com as mirabolâncias dos produtores de milagres eletrônicos.

\section{REFERÊNCIAS BIBLIOGRÁFICAS}

BARRETTO, E. S. S.; PINTO, R. P.; MARTINS, A. M. Formaação de docentes a distância: reflexões sobre um programa. Cadernos de Pesquisa, n. 106, p.81-1 I 5, mar. 1999.

BECKER, F. Epistemologia do professor: o cotidiano da escola. Petrópolis: Vozes, 1993.

BELINTANE, C. Relatório de pesquisa preparatória do curso "Ambiência de Leitura", elaborado para a rede escolar da Fundação Bradesco. São Paulo: mimeo, 2000, p.5.

BUENO, B. O. Pesquisa em colaboração na formação contínua de professores. In: BUENO, B.; CATANI, D. B.; SOUZA, C. P. A Vida e o oficio dos professores. São Paulo: Escrituras, 1988.

CHIAPPINI, L. A Circulação dos textos na escola - 2. In: BRANSÃO, H. N. Gêneros do discurso na escola: mito, conto, cordel, discurso político, divulgação científica. São Paulo: Cortez, 2000. [Coleção Aprender e Ensinar com Textos; v. 5]

JOHNSON, S. Cultura da interface: como o computador transforma nossa maneira de criar e comunicar. Rio de Janeiro: Zahar, 200I.

MIZUKAMI, M. G. N. Ensino: as abordagens do processo. São Paulo: EPU, 1986.

TAKAHASHI, T. (org.). Livro verde. Brasília: Ministério da Ciência e Tecnologia; Sociedade da Informática do Brasil, 2000. [Cap. 4: Educação na Sociedade da Informação]

Recebido em: março 2002

Aprovado para publicação em: maio 2002

4 Se esse texto fosse eletrônico, com certeza, teríamos um link para levar o leitor da palavra "maranha" ao verbete do dicionário "Aurélio" eletrônico, como não é, transcrevo o verbete: "MARANHA [De or. pré-romana, poss.] S. f. I. Porção de fibras ou fios enredados. 2. Teia de lã por apisoar. 3. Crespidão, grenha. 4. Fig. Coisa intrincada; emaranhamento, enredo, complicação, teia. 5.Intriga, embrulhada, confusão. 6. Combinação, conluio, pacto. 7. Astúcia, esperteza. 8. Bras., Amaz. Manha, velhacaria. 9. Bras., Amaz. Ação de furtar-se ao trabalho; malandragem. 